\title{
Educação para humanização: aproximações entre os pensamentos de Paulo Freire e Edgar Morin
}

\author{
Ettiène Guérios* \\ Sonia Maria Chaves Haracemiv** \\ Ana Maria Soek ${ }^{* * *}$
}

\section{Resumo}

O objetivo deste artigo é buscar aproximações teóricas, tendo a educação para humaniz̧ação como eixo, entre Paulo Freire e Edgar Morin, a fim de identificar fundamentos para a prática educativa. Trata-se de uma pesquisa de natureza qualitativa com abordagem interpretativa e descritiva do tipo narrativo, que analisa focalmente as obras Os sete saberes necessários à educação do futuro (MORIN, 2000) e Pedagogia da autonomia: saberes necessários à prática educativa (FREIRE, 1996). O estudo ocorreu por meio de um processo recursivo, dialógico e relacional, possibilitando identificar noções conceituais e interdependências aproximativas e complementares entre os pensamentos desses autores. Percebe-se que ambos acolhem diversos fundamentos para uma prática educativa que leve em conta: a consciência de inacabamento, uma visão ética, a contextualização entre o local e o global,

* Doutorado em Educação Matemática (UNICAMP). Professora no Programa de Pós Graduação em Educação (Acadêmico) e no Programa de Pós Graduação em Educação: Teoria e Prática de Ensino (Profissional) da Universidade Federal do Paraná (UFPR). E-mail: ettiene@ufpr.br ORCID: http://orcid. org/0000-0001-5451-9957

** Pós-Doutorado em Currículo e Avaliação (UNIRIO). Professora no Programa de Pós Graduação em Educação (Acadêmico) e no Programa de Pós Graduação em Educação: Teoria e Prática de Ensino (Profissional) da Universidade Federal do Paraná (UFPR). E-mail: sharacemiv@gmail.com http:/ / orcid.org/0000-0001-9305-5227

*** Doutorado em Educação (UFPR). Professora no Programa de Pós-graduação em Educação: Teoria e Prática de Ensino (Profissional) da Universidade Federal do Paraná (UFPR). E-mail: anasoek@gmail.com Orcid: http://orcid.org/0000-0002-4827-8242 
o diálogo, a esperança, a diversidade, a pluralidade, a compreensão, a tolerância e a complexidade da condição humana.

Palavras-chave: Complexidade; Diálogo; Prática Pedagógica; Formação de Professores; Desenvolvimento Humano

\section{Education for humanization: approximations between the thoughts of Paulo Freire and Edgar Morin}

\section{Abstract}

This article aims to link Paulo Freire's and Edgar Morin's ideas having as central axis "Education for Humanization", in order to identify similarities between them regarding the foundations for educational practice. This is qualitative research, with a descriptive and interpretive approach, of the narrative type, which analyzed the works "The seven essential knowledge in Education for the Future" (MORIN, 2000) and "Pedagogy of Autonomy: Necessary Knowledge for Educational Practice" (FREIRE, 1996). Terms expressing the authors' understanding of the central axis were listed. The analysis occurred through a recursive, dialogical, and relational process that made it possible to identify conceptual notions and approximate and complementary interdependencies between the thoughts of these authors. It can be seen that both authors embrace several foundations for an educational practice that takes into account: the consciousness of incompleteness, an ethical vision, the contextualization between local and global, dialogue, hope, diversity, plurality, understanding, tolerance, and the complexity of the human condition.

Keywords: Complexity; Dialogue; Pedagogical Practice; Teacher Education; Human Development; Complex Thought

\section{Educación para la humanización: aproximaciones entre el pensamiento de Paulo Freire y Edgar Morin}

\section{Resumen}

El objetivo de este artículo es entrelazar las ideas de Paulo Freire y Edgar Morin teniendo como eje central la "Educación para la Humanización", con el fin de identificar aproximaciones entre ambos en cuanto a los fundamentos para una práctica educativa. Se trata de una investigación cua- 
litativa, de enfoque descriptivo e interpretativo, de tipo narrativo, que se centró en las obras "Los siete saberes necesarios para la Educación del futuro" (MORIN, 2000) y "Pedagogía de la autonomía: Saberes necesarios para la práctica educativa" (FREIRE, 1996). Se enumeraron los términos que expresan la comprensión de los autores sobre el eje central. El análisis se produjo mediante un proceso recursivo, dialógico y relacional que permitió identificar nociones conceptuales e interdependencias aproximadas y complementarias entre los pensamientos de estos autores. Es posible notar que ambos autores abrazan varios fundamentos para una práctica educativa que tiene en cuenta: la conciencia de la incompletud, una visión ética, la contextualización entre lo local y lo global, el diálogo, la esperanza, la diversidad, la pluralidad, la comprensión, la tolerancia y la complejidad de la condición humana.

Palabras clave: Complejidad; Diálogo; Práctica pedagógica; Formación de Profesores; Desarrollo humano; Pensamiento complejo

\section{Introdução}

O ano de 2021 é realmente singular para a Educação, pois nele se comemora o centenário de dois importantes expoentes da área. Em 8 de julho de 1921, em Paris, nasceu Edgar Morin, e, em 19 de setembro de 1921, no Brasil, nasceu Paulo Freire. Dois pensadores da educação que versam, como marca de seus influentes trabalhos, sobre a educação para humanização, sobre as lutas pela dignidade humana, sobre a autonomia e sobre o direito à educação.

Paralelamente, em 2020 e 2021 surgem diversos desafios causados pela imprevista pandemia do coronavírus. Escolas e universidades fechadas, ensino remoto instituído, cotidiano interrompido pelo isolamento social, entre outras decorrências que se fizeram impostas, mostram o quanto estar aberto para o inesperado é diferencial para o enfrentamento de fatos que provocam crises imprevistas. A incerteza assola a todos, de modo especial os que perderam o que construíram em sua vida e precisam sobreviver. Nesse contexto, faz-se emergente falar em humanização, conscientização, cuidado com o outro, amorosidade e busca incessante por diálogo nos diferentes contextos sociais de convivência humana.

Neste momento, mais do que nunca, urge imperativamente, soluções menos conflitantes, imbuídas de amorosidade e respeito 
ao próximo, em que, por meio do cuidar de si, igualmente cuida-se do outro. Incessantemente, temos de nos dar conta de que todos estão no mesmo mundo, compartilhando um tempo-espaço comum que adquiriu novos contornos para a existência humana.

A atual pandemia está nos alertando para a necessidade de o homem temporalizar-se e humanizar-se, percebendo os descasos com a vida humana, as polarizações e dicotomias acentuadas, que, neste difícil momento, parecem agravar as desigualdades sociais e educacionais historicamente vividas, não só em nosso país, mas também no mundo.

Diante desse cenário, as obras de Edgar Morin e Paulo Freire refletem sobre a Educação como movimento de vida em construção, vida inacabada, vida em interação, vida completa e complexa; pois tratam das vidas que carregam mazelas, mas também as que carregam beleza, cuidado, amorosidade e humanidade do homem contemporâneo. Ambos os educadores se afirmaram como pensadores atemporais, imortais e presentes por meio das falas que

A intenção deste artigo, assim, é buscar aproximações teóricas entre ambos, de modo a visibilizar o que acolhem como fundamentos para uma prática educativa humanizadora, discutindo alguns fundamentos de suas teorias educativas no contexto das concepções ontológicas, epistemológicas e metodológicas dos dois autores. Para isso, consideramos as obras que mais circulam nos cursos de formação de professores, a saber: Pedagogia da autonomia: saberes necessários à prática educativa, de Paulo Freire, publicada em 1996, um ano antes de sua morte, e Os sete saberes necessários à educação do futuro, de Edgar Morin; esta, conforme informa Brito ${ }^{1}$ (2021), permanece sistematicamente como a obra mais acessada da biblioteca digital da UNESCO.

1 Lidia Brito é Diretora da Oficina Regional de Ciências da Unesco para a América Latina e o Caribe. Informação contida na apresentação da obra "Posibles, aún invisibles. Edgar Morin y el realismo de la utopía: los siete saberes y la Agenda 2030", publicada pela UNESCO (2021, p. 9). 


\section{Paulo Freire e os saberes necessários às práticas educativas}

Na obra Pedagogia da autonomia: saberes necessários à prática educativa, de 1996, a pedagogia libertadora, voltada à humanização, é alicerçada e estruturada a partir de três capítulos, nos quais Freire expõe seus fundamentos para a prática educativa, quase sempre iniciando os subtítulos com expressão de ênfase: "ensinar exige...".

À medida que vai discorrendo sobre as ações necessárias à prática educativa, Freire (1996) revela sua teoria crítica, suas denúncias do caráter da educação opressora, sua crítica ao sistema tradicional de educação, em que faz analogias a um "sistema bancário" ao revelar o educando como mero receptor dos ensinamentos do professor. Nesse caráter crítico, ele conduz sua lógica de educação ao diálogo, à educação em pares e à educação entre iguais. Outro importante fundamento proposto na obra é a noção de incompletude dos seres humanos, como seres inacabados em constante formação.

Freire (1996) propõe, desse modo, uma educação com visão transformadora. Para ele, o ser humano está em processo constante de aprendizagem, devendo ter consciência de sua inconclusão, de seu inacabamento, necessitando aprender, construir conhecimentos, interagir e dialogar com os outros. Sendo o diálogo transformador, o tomar consciência de que ainda é necessário aprender promove o questionamento da realidade e dos saberes, modificando a visão de si mesmo e do mundo. Nesse sentido, Freire afirma que “[...] me aproximo de novo da questão da inconclusão do ser humano, de sua inserção num permanente movimento de procura, que rediscuto a curiosidade ingênua e a crítica, virando epistemológica". Acentua ainda que "ensinar não é transferir conhecimento, mas criar as possibilidades para a sua produção ou a sua construção" (FREIRE, 1996, p. 16).

Desse modo, o educador não deve ser licencioso, permissivo, espontaneísta e autoritário, mas deve exercer a autoridade pela competência em sala de aula, atuando, democraticamente, com ética e criticidade, instigando, como mediador, o educando a se instru- 
mentalizar com conhecimento, que o qualifique a atuar no meio em que vive. Na visão de Freire, é preciso fazer a leitura do mundo por meio de seu contexto, pois a explicação do mundo de que faz parte está relacionada à compreensão de sua própria presença no mundo, sendo que "isso tudo vem explicitado ou sugerido ou escondido no que chamo 'leitura do mundo' que precede sempre a 'leitura da palavra"” (FREIRE, 1996, p. 81).

Nesse sentido, expõe-se também a concepção de educação como um ato político, de necessária conscientização. $\mathrm{O}$ educador enfatiza o desenvolvimento de autonomia, tanto do educador, quanto dos educandos, pois, ao se educarem, modificam a si mesmo e ao seu entorno social. Assim sendo, "a autonomia vai se constituindo na experiência de várias, inúmeras decisões que vão sendo tomadas. A autonomia, enquanto atitude do ser para si, é processo de vir a ser" (FREIRE, 1996, p. 121).

$\mathrm{Na}$ prática pedagógica, são imprescindíveis algumas rigorosidades metódicas, como, por exemplo, a necessidade de autoridade do educador, que é diferente de autoritarismo, pois "o professor que realmente ensina, quer dizer, que trabalha os conteúdos no quadro da rigorosidade do pensar certo, nega, como falsa, a fórmula farisaica do faça o que mando e não o que eu faço" (FREIRE, 1996, p. 12).

Segundo o autor, o ser humano é um sujeito histórico, transformador e ativo em seu processo de aprendizagem no mundo. A aprendizagem na educação transformadora necessita, então, que o docente, na sua ação didática, instigue seus aprendizes a pesquisar e a dialogar com autores e teorias, para que sejam sujeitos capazes de construir seus próprios conhecimentos por meio do interagir no mundo e com o mundo. Em outras palavras,

[...] reinsisto em que formar é muito mais do que puramente treinar o educando no desempenho de destrezas e por que não dizer também da quase obstinação com que falo de meu interesse por tudo o que diz respeito aos homens e às mulheres, assunto de que saio e a que volto com o gosto de quem a ele se dá pela primeira vez (FREIRE, 1996, p. 14, grifos nossos). 
Em suma, para Freire, na ação educativa, mediada pelo mundo na comunhão entre os homens, é que o homem se torna homem, no sentido de humanização.

\section{Edgar Morin e os saberes necessários à educação do futuro}

Em 1996, a UNESCO publicou o relatório da Comissão Internacional sobre Educação para o século XXI, coordenado por Jacques Delors, em que aponta quatro pilares para subsidiar políticas educacionais ao redor do mundo. São eles: aprender a conhecer, aprender a fazer, aprender a viver em conjunto e aprender a ser. Ponderando que a educação deve, necessariamente, visar à constituição do ser humano em sua integralidade, Nicolescu (1997) ${ }^{2}$ afirma que há uma "transrelação" que conecta esses pilares ${ }^{3}$. Na educação, tal transrelação vislumbra a compreensão do mundo pelo ser humano multidimensionalmente constituído, para estar no mundo de modo presente.

Com a mesma diretriz, a UNESCO encomendou a Edgar Morin a organização de uma obra que contemplasse princípios educativos para subsidiar, como referência, a educação do século XXI. Assim, com uma perspectiva complexa e transdisciplinar que possibilita a compreensão do homem no e para o mundo, a UNESCO publicou, em 1999, a obra Os sete saberes necessários à educação do futuro (edição brasileira de 2000), que se tornou referência para a promoção de uma educação que pense o ser humano. São eles: as cegueiras do conhecimento, o erro e a ilusão; os princípios do conhecimento pertinente; ensinar a condição humana; ensinar a identidade terrena; enfrentar as incertezas; ensinar a compreensão; a ética do gênero humano. Morin (2000, p. 13) alerta que esses são saberes fundamentais "que a educação deve tratar em toda sociedade e em

2 Conferência proferida no Congresso Internacional $A$ responsabilidade da Universidade para com a Sociedade. Bangkok, Thailand: International Association of Universities, Chulalongkorn University, 1997.

3 Jorge Werthein resgata essa ideia na introdução da edição brasileira da obra $O s$ sete saberes necessários à educação do futuro (WERTHEIN, 2000, p. 11). 
toda cultura, sem exclusividade nem rejeição, respeitando modelos e regras próprias a cada sociedade e a cada cultura". Ressalta-se e toma-se como uma máxima de seu dizer que "a educação do futuro deverá ser o ensino primeiro e universal centrado na condição humana" (MORIN, 2000, p. 45).

A atualidade da obra é indiscutível, de tal modo que Carrizo (2021) chama a atenção para o fato de que ela dialoga com os objetivos do documento adotado pela Assembleia Geral da Organização das Nações Unidas (ONU) em 2015, denominado Transformando o nosso mundo: a Agenda 2030 para o desenvolvimento sustentável. $\mathrm{O}$ processo de construção da agenda abrangeu dois anos de consulta pública intensiva junto à sociedade, envolvendo representantes dos 193 Estados-membros da ONU. Composto por 17 objetivos e 169 metas, trata-se de "um plano de ação para as pessoas, para o planeta e para a prosperidade. Ela também busca fortalecer a paz universal com mais liberdade" (ONU, 2015, p.1).

Olhando para e através dos pilares elencados por Delors (1997) e dos saberes, na verdade dos desafios, propostos por Morin (2000), consideramos que educação para bumanização está entre e além desses pilares, configurando-se como objetivo emergente, resultante de um movimento transrelacional entre os pilares e os saberes.

Desse modo, formação de professores, exercício da docência, aprendizagem de conteúdos escolares, aprendizagem para a vida e formação educativa num contexto planetário constituem uma teia complexa a qual a educação não pode se furtar. Com base na pertinência dessa teia, Guérios (2021) indagou sobre a formação de professores que tenha a humanidade planetária como princípio formativo, defendendo que, numa perspectiva complexa, a

[...] aprendizagem de conteúdos curriculares e a formação educativa constituem um binômio em que uma significa a outra, que, por sua vez, são pertinentes para uma escola criativa e transformadora, que tenha a Humanidade planetária como um princípio formativo e justiça social como meta (GUÉRIOS, 2021, p. 116). 
Educar para humanização, numa perspectiva complexa, transformadora e transdisciplinar, pressupõe o entrelaçamento dos sete saberes, visto a implicação mútua entre eles. Assim, "condição humana", "ética do gênero humano" e "compreensão" são simbióticas se o que se vislumbra é a vida terrena (humanidade planetária) fundada em "una cultura de convivencia para el desarrollo sostenible, la inteligencia colectiva, la comprensión mutua y la ciudadanía mundial" (CARRIZO, 2021, p. 16).

A ética da compreensão humana planetária requer compreensão do outro, exercício de tolerância, consideração do caráter ternário do gênero humano (indivíduo/sociedade/espécie), e de modo mais extremo, compreensão da incompreensão. Explica Morin (2000, p. 106) que os elementos da tríade indivíduo/sociedade/espécie são inseparáveis e coprodutores um do outro, sendo que "no seio desta tríade complexa emerge a consciência e nosso espírito propriamente humano". Extraímos, como decorrência das relações estabelecidas, que "a compreensão do outro requer a consciência da complexidade humana” (MORIN, 2000, p. 101).

Morin (2000, p. 13-14) reflete sobre o fato de que "a educação que visa a transmitir conhecimentos seja cega quanto ao que é o conhecimento humano, [...] e não se preocupe em fazer conhecer o que é conhecer", fato que precisa ser considerado no âmbito educacional. Evidencia, ainda, que todo o conhecimento comporta múltiplas e permanentes possibilidades de erro e de ilusão, pois

aquelas oriundas do exterior cultural e social inibem a autonomia da mente e impedem a busca da verdade; aquelas vindas do interior, encerradas, às vezes, no seio de nossos melhores meios de conhecimento, fazem com que as mentes se equivoquem de si próprias e sobre si mesmas (MORIN, 2000, p. 32-33).

Também merece destaque a observação de Morin (1998, p. 141) de que "a definição primeira do erro não se situa em relação à verdade", se tomarmos a verdade como resultante de verificações e confirmações, visto não haver uma verdade que sirva de medida ao erro. A concepção de conhecimento vinculada a esse entendimen- 
to de erro e ilusão não tem como cerne a unidimensionalidade da verdade fechada.

Dentre os desafios da complexidade, está o que se chama de pertinência do conhecimento. No mundo planetário, globalizado, o contexto do conhecimento de todas as naturezas é o próprio mundo, e é preciso que assim ele seja percebido. Por isso, preste-se atenção no alerta de Morin (2000) para a disjunção entre conhecimento e contexto, responsável pela fragmentação do conhecimento. Essa fragmentação dissocia partes da totalidade que as contém, impede relações delas com a complexidade inerente ao mundo e torna o conhecimento estéril e não pertinente. O pensamento mutilante é consequência dessa secessão. Segundo Morin (2000, p. 36), "temos de um lado os saberes compartimentados e divididos e do outro os problemas cada vez mais multidisciplinares, transversais, multidimensionais, transnacionais, globais e planetários".

Neste sentido, o conhecimento é multidimensional e uma de suas características é a incompletude. Para tentar unir o que o pensamento mutilante desfaz, a complexidade, mais propriamente o pensamento complexo, considera aspectos constitutivos do homem de diferentes naturezas, incluindo valores essenciais da existência humana, como, por exemplo, a humanização. Ampliando o espectro aqui abordado, Morin (1988, p. 177) afirma que:

[...] a aspiração à complexidade tende para o conhecimento multidimensional. Ela não quer dar todas as informações sobre um fenômeno estudado, mas respeitar suas diversas dimensões [...] não devemos esquecer que o homem é um ser biológico-sociocultural, e que os fenômenos sociais são, ao mesmo tempo, econômicos, culturais, psicológicos etc. Dito isto, ao aspirar a multidimensionalidade, o pensamento complexo comporta em seu interior um princípio de incompletude e de incerteza.

A realidade comporta, desse modo, mistérios e imprevisibilidade que demandam interrogação contínua. Num movimento chamado por Nicolescu (1997) de transrelacional, percebe-se a complexidade que associa Freire, Morin e Delors, visto que dela decorre 
a objetivação em aprender, com vista à educação para humanização e à humanidade planetária como princípio formativo.

\section{Percurso metodológico}

Esta é uma pesquisa de natureza qualitativa com abordagem interpretativa e descritiva do tipo narrativo, configurando-se como uma investigação realizada por pesquisadores de diferentes campos do conhecimento, especialmente da área de Educação. Assim sendo, possibilita-se interpretar as concepções das duas obras em sua complexidade, estabelecendo inter-relações a partir da aproximação e da compreensão de alguns conceitos encontrados nelas (MORAES; GALIAZZI, 2007).

Foram realizadas análises, a partir de reflexões e interpretações, para compreender os significados de conceitos latentes nas obras, de modo a realizar a configuração de sentido numa tecitura, numa nova interpretação. A busca pela aproximação compreendida e descrita exigiu considerar bases epistemológicas e fundamentos que nortearam a escrita e o desenvolvimento de saberes necessários às práticas educativas, segundo os dois pensadores, com vistas ao processo de humanização (MORAES; GALIAZZI, 2007).

Para compreensão quanto aos significados contidos nas obras de Morin e Freire, com palavras, conceitos e metáforas, buscou-se construir um diálogo explícito entre eles (MORAES; GALIAZZI, 2007). Foram elencados alguns termos na construção dessa compreensão, sendo que esses estão vinculados ao eixo central educação para humanização, buscando com isso representar o pensamento dos dois autores. Os termos escolhidos na descrição narrativa foram, a saber: rigorosidade metódica, criticidade, curiosidade, cegueiras do conhecimento, complexidade, aceitação do novo, mudança, inesperado, consciência do inacabamento, incerteza do conhecimento, especificidade humana, ética do gênero humano, condição humana, tolerância, esperança e liberdade.

O caminho metodológico, como procedimento de análise, levou as autoras a fazer um exercício de busca a partir dos significa- 
dos das palavras escolhidas. Esse procedimento auxiliou a identificar noções conceituais nas duas obras, possibilitando a reflexão por meio de relações dialógicas e recursivas e visibilizando interdependências aproximativas e complementares. Com vista à compreensão e à inter-relação, configurou-se um processo analítico-dialógico direcionado para a importância da descrição das palavras num movimento de leitura e releitura, a fim de que as compreensões fossem entrelaçadas e seus significados, ampliados entre os pensamentos dos referidos autores.

\section{Educação para humanização: tecendo diálogo e aproximações entre Morin e Freire}

Para que a educação seja promotora da humanização é preciso, antes de tudo, haver dialogicidade. Assim sendo, o que se pretende colocar em diálogo são as obras de Freire e Morin, de modo que haja "problematização do próprio conhecimento em sua indiscutível relação com a realidade concreta na qual se gera e sobre a qual incide, para melhor compreendê-la, explicá-la, transformá-la" (FREIRE, 2015, p. 66).

No entender de Morin (2000, p. 17), “a compreensão mútua entre os seres humanos, quer próximos, quer estranhos, é daqui para a frente vital para que as relações humanas saiam de seu estado bárbaro de incompreensão", o que pressupõem uma educação baseada no diálogo entre as pessoas, entre as ciências e entre o conhecimento de diferentes naturezas. E vai além, ao postular constituir-se em uma base da educação para a paz, "a qual estamos ligados por essência e vocação” (p. 17) Em complemento, Freire (1996, p. 50), ao explicitar a viabilidade do diálogo, afirma que "para viver a abertura respeitosa aos outros e, de quando em vez, de acordo com o momento, tomar a própria prática de abertura ao outro como objeto da reflexão crítica deveria fazer parte da aventura docente", por isso "o sujeito que se abre ao mundo e aos outros inaugura com seu gesto a relação dialógica em que se confirma como inquietação e curiosidade, como inconclusão em permanente movimento na História" (FREIRE, 1996, p. 50). 
Do mesmo modo, as autoras numa postura dialógica comungam com as palavras de Freire (1996, p. 50) quanto à necessária "disponibilidade permanente à vida a que me entrego de corpo inteiro, pensar crítico, emoção, curiosidade, desejo, que vou aprendendo a ser eu mesmo em minha relação com o contrário de mim".

Segundo Morin (2000), é pelo diálogo que novos saberes são construídos. Portanto, o diálogo que a escola deve desenvolver por ser um espaço de confrontação e diálogo de saberes, sejam eles formais, informais, particulares, populares, científicos - propicia a construção de novos saberes. Esses novos saberes deverão ter um sentido, uma validade, uma importância subjetiva e objetiva para a vida das pessoas, para que cada ser humano possa ter maior capacidade e poder de intervenção na sociedade, tornando-a, consequentemente, menos desumanizante e mais humanizada.

Em termos etimológicos e de acepções dicionarizadas, compreender está além do domínio de um objeto, pois inclui aquele que busca a compreensão. É um compreender como ato de conhecer e conhecer-se, conter em si, constar, abranger, perceber, entender e significar o espírito de complacência com as dificuldades (FREIRE, 2015).

Ao examinar as obras de Freire e de Morin elegidas para esta análise, junto de importantes conceitos de ações educativas para humanização nelas presentes, perceberam-se, além do diálogo e da capacidade comunicativa do ser humano, outras aproximações em relação ao entendimento do que é ser humano, ou seja, da ética do gênero humano, de sua condição humana propriamente dita.

Segundo Freire (1996), o homem, no e com o mundo, precisa ultrapassar o existir inerte e desenvolver a capacidade comunicativa com o mundo objetivo. Não apenas se adaptando, se acomodando ou se ajustando, pois se assim agir terá um comportamento desumano, uma visão de si desgarrada e suspensa, julgando o mundo pelo modo que o vê. Segundo Morin (2000), é preciso, assim, ensinar a condição humana, a ética do gênero humano, ensinar a compreensão. São saberes proclamados pelo pensador como alicerces para a educação do futuro, que se torna cada vez mais presente. 
Das análises das obras, nos foi cara a necessidade de compreensão e superação das visões simplistas, reducionistas e fragmentadas em relação às tratativas da educação e do conhecimento. Nessa perspectiva, reverbera-se o pensar no papel dialógico da educação, quando se traduz os vínculos entre ensino e aprendizagem, professores e estudante, e desses com o objeto de conhecimento a ser conhecido, compreendido, estudado. De forma a pensar em seus contextos locais, sem desconsiderar, porém, o global; pensar em nossas singularidades, sem desconsiderar, igualmente, a multiplicidade e a diversidade. Segundo Freire (1996, p. 19),

Assumir-se como ser social e histórico, como ser pensante, comunicante, transformador, criador, realizador de sonhos, capaz de ter raiva porque capaz de amar. Assumir-se como sujeito porque capaz de reconhecer-se como objeto. A assunção de nós mesmos não significa a exclusão dos outros. É a "outreidade" do "não eu”, ou do $t u$, que me faz assumir a radicalidade de meu $e u$.

Desses entendimentos, entre o eu e o outro, o uno e o diverso, o singular e o plural, a unidade e a diversidade, os opressores e os oprimidos, percebe-se, como outro grande ensinamento comum nas duas obras, a ideia de que o ser humano está em constante mudança, sendo ele um ser em construção. Morin (2000) afirma que a construção precisa passar pela consciência do inacabamento, pela consciência da ética universal, o que nos faz pertencer ao gênero humano.

Essa ética universal perpassa o diálogo entre os homens da terra, o respeito à diversidade, a noção de incompletude do ser humano e a consciência histórica, que se constrói ao longo de toda a sua vida, sujeita a retroações, recursividades e interações.

De acordo com Morin (2000, p. 114),

[...] a antropo-ética instrui-nos a assumir a missão antropológica do milênio no sentido de trabalhar para a humanização da humanidade; efetuar a dupla pilotagem do planeta: obedecer à vida, guiar a vida; alcançar a unidade planetária na diversidade; respeitar no outro, ao mesmo tempo, a diferença e a identidade quanto a si mesmo; desenvolver a ética da solidariedade; desenvolver a ética da compreensão; ensinar a ética do gênero humano. 
Freire (1996) acrescenta que os seres humanos constroem sua identidade pessoal e social em contextos históricos e culturais, a partir de processos relacionais consigo mesmo, com os outros e com o mundo. Para tanto, é imprescindível assumir-se, uma das tarefas mais importantes na prática educativa. Desse modo,

[...] propiciar as condições em que os educandos em suas relações uns com os outros e todos com o professor ou a professora ensaiam a experiência profunda de assumir-se como ser social e histórico, como ser pensante, comunicante, transformador, criador, realizador de sonhos, capaz de ter raiva porque capaz de amar (FREIRE, 1996, p. 18).

Segundo Freire (1996, p. 33), cabe ao "professor ou, mais amplamente, à escola, o dever de não só respeitar os saberes [...] dos educandos, socialmente construídos na prática comunitária”. A aproximação entre Morin e Freire, dessa maneira, trata sobre a importância dos saberes docentes e o modo como esses são construídos e se manifestam nas relações do homem. Para Morin (2000, p. 33), considera-se, enfatizando as questões do aprender, que o "imprinting cultural marca os humanos desde o nascimento, primeiro com o selo da cultura familiar, da escolar, depois prossegue na universidade ou na vida profissional".

A principal preocupação, em suma, dos autores é indicar ações educativas como forma de superação dos dogmatismos de concepções desumanizantes, propondo possibilidades para uma reforma do pensamento que seja transformadora e libertadora.

\section{Considerações}

$\mathrm{Na}$ realização desta pesquisa, o movimento recursivo de ler, refletir, reler e interpretar a literatura dos pensamentos de Freire e Morin selecionada para análise possibilitou para as autoras o encontro de aproximações entre as obras, que tratam de fundamentos para a formação docente com vistas a uma prática pedagógica transformadora e humanizante, mediada, principalmente, pelo diálogo e pelo reconhecimento de pertencimento a uma ética universal humana comum a todos. 
Das aproximações dos pensamentos de Morin (2000) e de Freire (1996), acentua-se a necessidade de falar cada vez mais de educação para humanização, marcados pela bela coincidência quanto ao centenário de nascimento desses renomados educadores.

Para isso, os autores enfatizam a urgência na superação de modelos de educação conservadora, baseada em estigmas tradicionais. Nesse sentido, Morin (2000) defende a transitoriedade do conhecimento ao salientar que aprender a conhecer é enfrentar as incertezas desse conhecimento e estar aberto ao novo e ao inesperado.

Da análise das referidas obras, realçou-se a necessária compreensão e superação das visões reducionistas e fragmentadas em relação às tratativas da educação e do conhecimento. Reverbera-se essa compreensão educacional, por extensão, no papel dialógico nas relações de ensino e aprendizagem, nas relações entre professores e estudantes, nas relações com o objeto de conhecimento a ser compreendido e nas relações com seu contexto local, sem desconsiderar o global. Tudo isso remete a pensar em singularidades, sem desconsiderar, porém, a multiplicidade e a diversidade.

Para Freire (1996, p. 73), "há uma relação entre a alegria necessária à atividade educativa e a esperança”, compreendendo o mundo como espaço de aprendizagem e o saber histórico como possibilidade e não como "determinação", como parte do processo humanizador, em contestação à abordagem histórica limitadora e fragmentária. Em suas palavras, aprender é "construir, reconstruir, constatar para mudar, o que não se faz sem abertura ao risco e à aventura do espírito" (FREIRE, 1996, p. 69). Para Morin (1988, 2000), a vida é aventura e o risco é componente do imprevisível, pois os acontecimentos não são controláveis e programáveis.

Para Morin (2000), a nossa preocupação primeira e universal deve ser a educação centrada na condição humana, pois

Estamos na era planetária; uma aventura comum conduz os seres humanos, onde quer que se encontrem. Estes devem reconhecer-se em sua humanidade comum e ao mesmo tempo reconhecer a diversidade cultural inerente a tudo que é humano. Conhecer 
o humano é, antes de tudo, situá-lo no universo, e não separá-lo dele. [...] todo conhecimento deve contextualizar seu objeto, para ser pertinente. "Quem somos?" é inseparável de "Onde estamos?", "De onde viemos?", "Para onde vamos?” Interrogar nossa condição humana implica questionar primeiro nossa posição no mundo (MORIN, 2000, p. 51).

Outra aproximação entre Morin e Freire é a tratativa sobre a importância dos saberes docentes e a construção e manifestação deles nas relações humanas pedagógicas. Morin (2000, p. 51) complementa essa importância, dizendo que

[...] o conceito de homem tem duplo princípio; um princípio biofísico e um psico-sócio-cultural, um remetendo ao outro. [...] o homem somente se realiza plenamente como ser humano pela cultura e na cultura. [...] A hominização conduz a novo início. O hominídeo humaniza-se.

Há preocupação dos autores em indicar ações educativas como possibilidade de superação dos dogmatismos apresentados nas concepções desumanizantes, propondo, para isso, indicadores para uma reforma do pensamento, de fato transformadora e libertadora.

Há que haver uma ética universal que deve ser perpassada pelo diálogo entre os homens da terra, o respeito à diversidade, a noção de incompletude do ser humano, a consciência histórica de sujeito inacabado e a construção que se desenvolve ao longo de toda a sua vida, que está suscetível a retroações, recursividades e interações. De acordo com Morin (2000, p. 114),

a antropo-ética instrui-nos a assumir a missão antropológica do milênio no sentido de trabalhar para a humanização da humanidade; efetuar a dupla pilotagem do planeta: obedecer à vida, guiar a vida; alcançar a unidade planetária na diversidade; respeitar no outro, ao mesmo tempo, a diferença e a identidade quanto a si mesmo; desenvolver a ética da solidariedade; desenvolver a ética da compreensão; ensinar a ética do gênero humano.

Por meio do diálogo, novos saberes serão construídos, sendo que eles deverão ter um sentido, um significado, uma importância 
subjetiva e objetiva para a vida das pessoas, a fim de que um de nós possa intervir na sociedade e, consequentemente, torná-la menos desumanizante e mais humanizada.

\section{Referências}

BRITO, L. Presentación. In: UNESCO. Posibles, aún invisibles: Edgar Morin y el realismo de la utopía: los siete saberes y la Agenda 2030. 2021. p. 9-11.

CARRIZO, L. Introducción. In: UNESCO. Posibles, aún invisibles: Edgar Morin y el realismo de la utopía: los siete saberes y la Agenda 2030. 2021. p. 15-19.

CONGRESSO INTERNACIONAL A RESPONSABILIDADE DA UNIVERSIDADE PARA COM A SOCIEDADE. Bangkok, Thailand: International Association of Universities, Chulalongkorn University, 1997.

FREIRE, P. Extensão ou comunicação? Rio de Janeiro: Paz e Terra, 2015.

FREIRE, P. Pedagogia da autonomia: saberes necessários à prática educativa. 4 . ed. Rio de Janeiro: Paz e Terra, 1996.

GUÉRIOS, E. Prática pedagógica na perspectiva da complexidade: articulação entre educação matemática e educação para a vida. Revista Polyphonía, [s. l.], v. 32, n. 1, p. 100-117, 2021. Disponível em: https://www.revistas.ufg.br/sv/article/ view/67393. Acesso em: 20 jul. 2021.

MORAES, R.; GALIAZZI, M. C. Análise textual discursiva. Ijuí: Editora Unijuí, 2007.

MORIN, E. Ciência com consciência. Rio de Janeiro: Bertrand Brasil, 1998.

MORIN, E. Os sete saberes necessários à educação do futuro. Tradução de Catarina Eleonora F. da Silva e Jeanne Sawaya. São Paulo: Cortez; Brasília, DF: UNESCO, 2000.

NICOLESCU, B. A evolução transdisciplinar e a universidade: condição para o desenvolvimento sustentável. Centre International de Recherches et Études Transdisciplinaires (Ciret), 1997. Atualização em: 2012. Disponível em: https:// ciret-transdisciplinarity.org/bulletin/b12c8por.php. Acesso em: 22 jul. 2021.

ONU. Transformando nosso mundo: a Agenda 2030 para o desenvolvimento sustentável. 2015. Preâmbulo. Disponível em: https://brasil.un.org/pt-br/ 91863-agenda-2030-para-o-desenvolvimento-sustentavel. Acesso em: 23 jul. 2021. 
UNESCO. Educação, um tesouro a descobrir: relatório para a UNESCO da Comissão Internacional sobre Educação para o século XXI. Título original: Learning, the treasure within: report to UNESCO of the International Commission on Education for the Twenty-first Century. Coordenado por Jacques Delors. Tradução de José Carlos Eufrázio. São Paulo: UNESCO; Cortez, 1997. Edição brasileira.

WERTHEIN, J. Apresentação da edição brasileira. In: MORIN, E. Os sete saberes necessários à educação do futuro. 1. ed. Tradução de Catarina Eleonora F. da Silva e Jeanne Sawaya. São Paulo: Cortez; Brasília, DF: UNESCO, 2000. 